\title{
Experimental observations of active blade pitch and generator control influence on floating wind turbine response
}

\author{
Andrew J. Goupee ${ }^{1 *}$, Richard W. Kimball ${ }^{2}$ and Habib J. Dagher ${ }^{3}$
}

\begin{abstract}
In this paper, the influence of wind turbine blade pitch and generator controls on the global response of a floating wind turbine is investigated. Several different active turbine controllers are considered and the resulting floating wind turbine global response is compared with that for a baseline configuration employing a fixed blade pitch and a fixed rotor speed. Results from platform pitch free-decay tests as well as a simultaneous dynamic wind and irregular sea state condition are used to understand the controllers' influence on floating wind turbine dynamic behavior.
\end{abstract}

Keywords: Floating, wind, turbine, control, semi-submersible

\section{Introduction}

Floating offshore wind turbine technology shows great promise as it enables the harnessing of abundant, clean renewable deep water wind energy [1]. However, the technology is not yet commercially mature and there are several areas where further research and development may permit smarter, more economical designs. One area of great interest pertains to active turbine blade pitch and generator controls and their influence on the coupled dynamic response of floating wind turbines [2]. Jonkman [3] showed through simulation that standard land-based controls aimed at regulating power generation can induce platform pitch instabilities for floating wind turbines with compliant foundations. Numerous researchers have worked towards developing floating wind turbine-specific turbine control strategies that prevent such instabilities, mitigate loads and properly regulate power using theoretical frameworks and simulation (e.g. see [4-13]). Despite the great interest in the topic, little work has been done experimentally to understand the influence of active turbine controls on floating wind turbine global performance. Azcona et al. [14] performed model-scale experiments of a semi-submersible floating wind turbine that incorporated aerodynamic thrust using a ducted fan which was controlled via a realtime numerical simulation with active turbine controls. Huijs et al. [15] also performed modelscale testing of a floating turbine with active turbine controls in a wind/wave basin, albeit with a fully-functioning wind turbine operating in a Froude-scaled wind environment. Both Skaare et al. [16] with the Hywind Demo and Viselli et al. [17] with the VolturnUS 1:8 have performed numerical model correlation studies with experimental data from ocean-deployed prototypes employing active turbine controls. One of the few works that goes beyond simply incorporating turbine controls into the experiment and begins to explore the influence of control parameters on turbine performance can be found in Chujo et al. [18]. Chujo et al. performed 1/100th-scale experiments in a wind/wave basin and altered turbine blade pitch control parameters to understand their impact on rotor speed and platform pitch motion variation for a spar-based floating wind turbine. 
In light of the limited experimental study of active turbine controls and their impact on floating wind turbine global performance, the DeepCwind Consortium, led by the University of Maine, performed a series of $1 / 50^{\text {th }}$-scale model tests at the Maritime Research Institute Netherlands (MARIN) Offshore Basin of a floating wind turbine employing various active turbine control schemes. The experiments, which were performed on a semi-submersible-based floating wind turbine, provide insight into the alterations in system motions and loads resulting from various wind turbine controller strategies. Of particular interest in this work are the changes in the frequency domain response, phase of the response relative to the environmental inputs and response statistics for select quantities that typically respond strongly to aerodynamic loads. Specifically these quantities include the platform surge motion, platform pitch motion, nacelle surge acceleration and upwind fairlead tension. In addition, the controller actuation behaviors are also studied.

\section{Model Test Description}

For this campaign, the model tests were performed in MARIN's Offshore Basin [19]. The directions of the winds and waves produced in the basin, in addition to the orientations of the rigid-body degrees of freedom (DOF), are depicted in Fig. 1. All model particulars and test data was reported at full scale by MARIN. As such, all values reported in this paper are presented at full scale.

\subsection{Environmental Conditions}

The operating environment used for investigating the influence of wind turbine controls on global performance consists of a dynamic wind and irregular sea state. The dynamic wind as measured at the hub-height location of $90 \mathrm{~m}$ above the mean water line follows a National Petroleum Directorate (NPD) spectrum [20] with a mean hub-height wind speed of $21.02 \mathrm{~m} / \mathrm{s}$. The NPD spectrum is distinct from spectra specified in standards for use in typical turbine simulation in that it only specifies the temporal variation in the longitudinal direction (i.e., negative surge direction here) at the hub height and does not prescribe any realistic spatial variation in the features of the wind inflow. This simplistic spectrum is well suited for wind/wave basin testing as achieving temporally varying, albeit spatially uniform flows over the rotor plane area constitutes the limit of the current state-of-the-art in wind field generation for open-jet wind machines found in wave basins as used in this test campaign. That noted, this wind speed lies between the rated and cut-out wind speeds for a typical commercial wind turbine where active blade pitch control is relied upon to regulate turbine power. Wind speeds below rated, where blade pitch control is not used and only variable speed generator controls are employed, are not of interest in this work and are not considered here. The irregular sea state follows a Joint North Sea Wave Project (JONSWAP) spectrum [21] representative of a 1-year event as found in the Gulf of Maine [22]. The statistics for the dynamic wind and irregular wave can be found in Tables 1 and 2, respectively. Note that in the tables $\sigma$ is the standard deviation, $H_{s}$ is the significant wave height, $T_{p}$ is the peak spectral period and $H_{\max }$ is the maximum wave height. The target and measured power spectral density (PSD) as a function of frequency for each of these environmental conditions is given in Fig. 2.

\subsection{Model Properties}

The floating wind turbine used for these tests was comprised of the DeepCwind semisubmersible supporting the MARIN stock wind turbine. Specifically, the configuration is the one currently being studied for the International Energy Agency's Wind Task 30: Phase II OC5 
project. Images of the system being tested in the MARIN Offshore Basin, which was moored by three catenary chains, are shown in Fig. 3. Specific details on the turbine can be found in de Ridder et al. [23] and Kimball et al. [24]. Additional details for the hull are located in Goupee et al. [25]. A brief overview of the gross system properties are given in Table 3.

A comparison of the normalized full-scale target (National Renewable Energy Laboratory 5 MW reference wind turbine [26]) and model wind turbine performance as measured at a steady hubheight wind speed of $12.91 \mathrm{~m} / \mathrm{s}$ over various rotor speeds using a collective blade pitch angle of $1.0^{\circ}$ is provided in Fig. 4. The figure shows that the thrust coefficient $C_{T}$ is similar between the full-scale target and model turbines allowing for the production of the correct aerodynamic thrust loads in the Froude-scaled wind environments of the basin. And while short of the full-scale target, the figure also indicates that the model turbine produces a reasonable performance coefficient $C_{P}$. The ability of the turbine to produce a fair amount of power under Froude-scaled winds enables the execution of experiments with realistic active turbine controls as the primary objective of wind turbine controllers is the regulation of power. $C_{T}$ and $C_{P}$ definitions can be found in [27].

\subsection{Blade Pitch Controller Descriptions}

In addition to a fixed blade pitch test with a constant rotor speed, two types of active blade pitch control algorithms were utilized. Both algorithms employ collective blade pitch actuation. The first was a simple, robust algorithm developed by MARIN that uses integral control to reduce the error on generator power with a target of $3.5 \mathrm{MW}$. The rotor speed was maintained at a constant $12.1 \mathrm{rpm}$ using a separate control loop. MARIN devised this control strategy as a backup to a more standard variable rotor speed configuration in an effort to de-risk the test campaign and protect the expensive MARIN stock wind turbine model. This particular controller allows precise regulation of the rotor speed for start-up, shut-down and general operation during testing and prevents possible damage to the model due to potential rotor over-speed scenarios. And while the controller was not entirely representative of a full-scale controller, it did permit a safe means for exploring the influence of active blade pitch control on floating wind turbine response. As such, this controller was used for a good part of the test campaign. During testing, several integral gains were investigated by changing the integrator gain constant $C_{i}$. Responses associated with constants of $C_{i}=25 \times 10^{5} \mathrm{~W} / \mathrm{s}$ and $C_{i}=100 \times 10^{5} \mathrm{~W} / \mathrm{s}$ are considered in this work. These values were chosen through experimentation in the basin, with the final values providing reasonable power control and blade pitch motion while still being distinct in their respective global performance. The actual gain $K_{i}$ is computed as $C_{i}$ divided by the sensitivity of rotor power to collective blade pitch angle $\partial P / \partial \theta . \partial P / \partial \theta$, which is a function of collective blade pitch angle, was derived from MARIN Stock Wind Turbine performance data taken prior to the basin tests and had the form

$$
\frac{\partial P}{\partial \theta}=8.56 \times 10^{6}-4.96 \times 10^{6} \theta \mathrm{W} / \mathrm{rad},
$$

where $\theta$ is the collective blade pitch angle in radians. The second controller, specified by the University of Maine, attempted to emulate a simple but realistic proportional-integral collective blade pitch control algorithm that seeks to minimize rotor speed error based on a target of 12.1 $\mathrm{rpm}$. This control algorithm also uses a variable speed generator control with the target torque being proportional to the square of rotor speed below $12.1 \mathrm{rpm}$, and equal to a constant value of $2690 \mathrm{kN}-\mathrm{m}$ at or above $12.1 \mathrm{rpm}$. The variable rotor speed aspect of this controller was viewed as more risky to implement by the MARIN staff, and hence, was used only in a limited fashion 
near the end of test campaign once the bulk of the data was collected. The proportional and integral gains for the blade pitch controller are computed in accordance with the equations of [28] using a recommended damping ratio of 0.7 and the aforementioned $\partial P / \partial \theta$ function. The controller frequency $\omega_{n}$ is set to $0.6 \mathrm{rad} / \mathrm{s}$ for the case studied in this paper and was chosen while tuning the controller in the basin so as to achieve reasonable rotor speed variations and blade pitch motions. For the remainder of this work, the constant rotor speed control schemes will be labeled CS25 and CS100 for control gains of $C_{i}=25 \times 10^{5} \mathrm{~W} / \mathrm{s}$ and $C_{i}=100 \times 10^{5} \mathrm{~W} / \mathrm{s}$, respectively. The variable speed control scheme will be denoted as VS. For the fixed blade pitch, fixed rotor speed controller, a designation of FF will be used.

\section{Free-decay Response}

Prior to combined wind/wave testing of the floating wind turbine system, simple platform pitch free-decay tests were performed to begin assessing the influence of controller behavior on platform pitch dynamics. While motions other than platform pitch were excited during these tests, in particular yaw motions due to rotor-related gyroscopic effects, these non-platform pitch motions were relatively small compared to the primary platform pitch motion and did not exhibit any discernable trends associated with the turbine controller selected. That noted, the cases considered include no wind with feathered blades $\left(\theta=90^{\circ}\right)$ to reduce aerodynamic drag, a fixed rotor speed and fixed blade pitch $\left(\theta=17.2^{\circ}\right)$ configuration (FF) subjected to a steady $21.19 \mathrm{~m} / \mathrm{s}$ wind and each of the three aforementioned controller configurations subjected to the same steady $21.19 \mathrm{~m} / \mathrm{s}$ wind. Fig. 5 and Fig. 6 display the platform pitch free-decay time series corrected for the mean offset (i.e., the steady-state platform pitch angle is subtracted from the response) and damping ratio as a function of initial cycle amplitude, respectively, for each of the five turbine configurations considered. As seen in the figures, all of the operating turbine scenarios increase the platform pitch damping appreciably. And while there were some distinctions between the FF case and the scenarios using a controller, overall they each seem to provide a reasonably similar increase in overall platform pitch damping.

The influence of the particular control scheme on the platform pitch dynamic response becomes more prominent when considering the change in the platform pitch damped natural period as shown in Table 4. It is worth noting that the steady-state mean platform pitch angle is essentially 0.0 degrees for the case with no wind and a small value of approximately $2.2-2.4^{\circ}$ for the remaining cases with wind. Therefore, any observed differences in the damped natural period between the configurations are not likely attributable to nonlinear hydrostatic effects. That stated, Table 4 indicates that the operating case sans controller does not significantly alter the platform pitch damped natural period; the three cases employing an active turbine controller each increase the damped platform pitch period with the CS100 controller lengthening the period by $10.5 \%$ over the base case performed in the absence of wind. These observed increases are not due solely to the growth in the damping observed in Fig. 6. The platform pitch damping increases observed for the operating turbine cases in Fig. 6 can only account for at most $\sim 1 \%$ of the lengthening of the damped natural pitch period. Lengthening of the platform pitch damped natural period as observed in the tests requires more drastic changes than just an increase in damping. As will be discussed in the subsequent section, it is suspected that the root cause is a controller-induced change in the platform pitch stiffness $C_{P i t c h}$. Table 4 displays an estimate of the required change in the platform pitch stiffness $\Delta C_{P i t c h}$ to achieve the measured change in the platform pitch damped natural period. For the fixed rotor speed and fixed blade pitch condition, almost no change in the pitch stiffness is observed; for the CS100 control scheme a drastic 
$18.0 \%$ reduction in the effective platform pitch stiffness is required to account for the alteration of the platform pitch damped natural period.

\subsection{Controller-induced Platform Pitch Period Elongation}

In an attempt to explain the damped platform pitch elongation displayed in Table 4, the mathematical techniques outlined in [3] are applied to the control scheme utilized in the test program. To begin, the equation of motion for the platform pitch DOF is cast in terms of the surge displacement $x$ of the hub-height location as done in [3] giving

$\frac{A_{\text {Pitch }}}{L^{2}} \ddot{x}+\frac{B_{P i t c h}}{L^{2}} \dot{x}+\frac{C_{\text {Pitch }}}{L^{2}} x=T$,

where $A_{\text {Pitch }}$ is the combined physical and added inertia for the platform pitch DOF, $B_{P i t c h}$ is the linearized platform pitch damping coefficient resulting from radiation and viscous effects, $C_{P i t c h}$ is a combination of linear hydrostatic and mooring line platform pitch DOF stiffness, $L$ is the hub height of the rotor and $T$ is the aerodynamic rotor thrust. Considering variations in $T$ with hubheight wind speed and blade pitch orientation, a first-order Taylor series expansion yields

$T=T_{o}-\frac{\partial T}{\partial U} \dot{x}+\frac{\partial T}{\partial \theta} \Delta \theta$,

where $T_{o}$ is the aerodynamic rotor thrust at a linearization point, $U$ is the wind speed averaged over the rotor area and $\theta$ is the collective blade pitch angle as noted previously. For the constant rotor speed, active blade pitch control scheme (i.e. CS25 and CS100), the perturbation in collective blade pitch angle $\Delta \theta$ is

$\Delta \theta=K_{i} \int_{0}^{t} \Delta P d t$

where $K_{i}$ is the integral control gain and $P$ is the rotor power. The rotor power $\mathrm{P}$ can be expanded in a similar fashion to the rotor thrust giving

$P=P_{o}-\frac{\partial P}{\partial U} \dot{x}+\frac{\partial P}{\partial \theta} \Delta \theta$

with $P_{o}$ being the rotor power at the linearization point. Noting that $\Delta P=P-P_{o}$, Eqs. 4 and 5 can be combined to produce

$\Delta \theta=K_{i} \int_{0}^{t}\left(-\frac{\partial P}{\partial U} \dot{x}+\frac{\partial P}{\partial \theta} \Delta \theta\right) d t=-K_{i} \frac{\partial P}{\partial U} x+K_{i} \frac{\partial P}{\partial \theta} \int_{0}^{t} \Delta \theta d t$.

Substitution of Eq. 6 into Eq. 3 yields

$T=T_{o}-\frac{\partial T}{\partial U} \dot{x}+\frac{\partial T}{\partial \theta}\left(-K_{i} \frac{\partial P}{\partial U} x+K_{i} \frac{\partial P}{\partial \theta} \int_{0}^{t} \Delta \theta d t\right)$.

Inserting the expression for $T$ from Eq. 7 into the platform pitch DOF equation of motion Eq. 2 gives

$\frac{A_{P i t c h}}{L^{2}} \ddot{x}+\left(\frac{B_{P i t c h}}{L^{2}}+\frac{\partial T}{\partial U}\right) \dot{x}+\left(\frac{C_{P i t c h}}{L^{2}}+K_{i} \frac{\partial T}{\partial \theta} \frac{\partial P}{\partial U}\right) x=T_{o}+K_{i} \frac{\partial P}{\partial \theta} \int_{0}^{t} \Delta \theta d t$.

Of interest in Eq. 8 is the term multiplying $x$ as this represents the platform pitch stiffness for the equation of motion cast in terms of the hub-height surge motion. Note that in addition to the stiffness $C_{\text {Pitch }} / L^{2}$ provided by hydrostatics and the mooring system, an additional term is included involving the integral control gain $K_{i}$, the sensitivity of the aerodynamic thrust to changes in collective blade pitch angle $\partial T / \partial \theta$ and the sensitivity of the rotor power to changes in wind speed $\partial P / \partial U$. Since $K_{i}$ is positive, $\partial T / \partial \theta$ is negative and $\partial P / \partial U$ is positive, the 
effective platform pitch stiffness is less than the pitch stiffness provided through hydrostatics and mooring alone. In addition, if the controller is turned off, then $K_{i}$ is effectively zero and the pitch stiffness is unaltered which agrees with the experimental results. This simple mathematical result provides a plausible explanation as to why the presence of an active blade pitch controller elongates the platform pitch damped natural period. Granted, the derivation does not apply to the VS controller; however, the findings displayed in Table 4 and in [25] indicate that a similar phenomenon occurs for this turbine control scheme.

\section{Response in Combined Wind and Waves}

When subjected to the wind and wave environments of Fig. 2, the global response of the DeepCwind-OC5 floating wind turbine differs depending on the particular turbine control scheme employed. Of particular interest here are platform rigid body motion, nacelle acceleration and mooring loads. In addition, the turbine actuation responses that give rise to the altered global performance behaviors are also of interest. The response of the FF configuration and the deviations the various control schemes produced from the base configuration are now discussed.

\subsection{Platform Motion}

For the wind and wave orientations of Fig. 1, the platform DOF which are most strongly influenced by changes in the turbine controller are surge and pitch. Fig. 7a depicts the PSD of the platform surge as measured at the mean water line for the FF case and Fig. $7 \mathrm{~b}$ the deviation $\Delta$ from this base case caused by the various control schemes. As seen in Fig. 7a, the surge response is dominated by low-frequency slow drift motion near the platform's surge damped natural frequency of $0.0094 \mathrm{~Hz}$; the response in the wave energy frequency range $(>0.06 \mathrm{~Hz})$ is significantly smaller. The dominant low-frequency response is attributable primarily to secondorder difference-frequency wave diffraction forces with the dynamic wind increasing the surge response slightly for frequencies less than $0.02 \mathrm{~Hz}$. The increases in surge response due to wind loading in the FF case over a baseline test using wave loads only and a parked wind turbine in calm air are approximately $50 \mathrm{~m}^{2} / \mathrm{Hz}$. When the controller is enabled, large reductions in the low-frequency surge motion are achieved with the CS100 controller exhibiting the largest reductions and the CS25 the least. The decreases attained with the various controllers yield lowfrequency surge responses that are similar to, or less than, a corresponding wave-only case with a parked wind turbine and no wind applied. For the CS100 controller, the peak frequency domain response is reduced by $42 \%$. For all of the controllers, no appreciable change in the response is observed in the wave energy frequency range.

Fig. 8a shows the phase shift in the platform surge response relative to the environmental excitations for the FF configuration. Note that for this and subsequent figures of this type, the phase shift of the response is computed relative to the dynamic wind speed at the hub-height location for frequencies less than $0.065 \mathrm{~Hz}$ and is computed relative to the irregular wave elevation at the undisplaced location of the platform for frequencies greater than $0.065 \mathrm{~Hz}$. As seen in Fig. 2, this is a reasonable choice for the distinction between the primary wind and wave excitation regimes. It should be noted that this methodology will yield phase shift curves that are not continuous at $0.065 \mathrm{~Hz}$. This transition point will be noted in all relevant figures. Moving to Fig. $8 \mathrm{~b}$, which shows the change in the phasing relative to the base case for each of the controllers, it is observed the controllers have little influence in the surge response phase in the wave energy regime; in the wind energy regime the phasing of the response is altered 
significantly. For all cases, the phasing is altered the most near the platform surge and pitch damped natural frequencies of $0.0094 \mathrm{~Hz}$ and $0.031 \mathrm{~Hz}$, respectively.

To complete the surge discussion, the platform surge statistics for the base case and the deviations caused by the three turbine controllers is presented in Table 5. As seen in the table, the mean surge is very similar for all cases. The standard deviation and range, however, are significantly reduced for all of the controller cases. The CS100 controller achieves the largest reduction of all the controllers in each of these metrics.

The platform pitch PSD for the FF configuration and deviation from this response caused by the various turbine controllers are shown in Fig. 9a and Fig. 9b, respectively. Similar to the surge response, the platform pitch frequency domain response for the FF case is dominated by the lowfrequency motion occurring near the corresponding DOF damped natural pitch frequency $(0.031$ $\mathrm{Hz}$ for platform pitch). The response in the primary wave energy frequency range is much smaller. As shown in Fig. 9b, all of the controllers reduce the platform pitch response for very low frequencies $(<0.005 \mathrm{~Hz})$. The VS controller reduces the response all the way up to $0.04 \mathrm{~Hz}$ with the exception of a minute increase at the platform pitch natural frequency. The CS25 controller increases the response in the range of $0.01-0.04 \mathrm{~Hz}$, albeit only slightly. The CS100 controller behaves similar to the VS controller except near the platform pitch natural frequency where it induces a severe increase in platform pitch response. The CS100 controller increases the peak frequency domain response for platform pitch by $113 \%$. For all of the controllers, no observable change occurred in the wave energy frequency range.

Moving to Fig. 10, the platform pitch response phase shift for the FF case and the deviations from this baseline for the various controllers is given. Again, Fig. 10b shows no appreciable phase shift for frequencies dominated by wave excitation for the three controllers. Each of the controllers exhibit similar changes in the pitch response phasing relative to the wind excitation with some of the phase shifts over this frequency range being quite large.

To complete the discussion for this particular platform DOF, the FF configuration platform pitch statistics as well as the changes resulting from different turbine controllers is given in Table 6. For each case, the mean pitch angle is fairly similar. All of the controllers diminish the standard deviation and range. This is somewhat surprising considering the large increase in the peak frequency domain response for the CS100 controller. Of the three controllers, the VS configuration provides the most drastic reductions in platform pitch standard deviation and range.

\subsection{Nacelle Acceleration}

The frequency domain response of the surge-direction nacelle acceleration for the FF configuration is given in Fig. 11a. Part b of the figure displays the deviation from this response for the three different turbine controllers. As one would expect from Fig. 11a, nacelle surge acceleration responses do exist beyond the $0.14 \mathrm{~Hz}$ limit provided in the figure, much of it due to wave excitation from the higher-frequency components of the irregular sea state. However, the responses beyond this frequency are essentially the same for all four scenarios considered here, and therefore do not provide much insight into the differences between the various control schemes. Another contribution to the nacelle surge acceleration above $0.14 \mathrm{~Hz}$ can be attributed to the elasticity of the tower (fore-aft bending frequency of $0.32 \mathrm{~Hz}$ as noted in Table 3), albeit 
much of this response is muted by the presence of aerodynamic damping (e.g. see [29]). As such, the overall nacelle surge acceleration is dominated by the pitch motion of the platform. With that in mind, it is unsurprising that the trends observed in Fig. 11 for nacelle acceleration are similar to those found for platform pitch in Fig. 9. The one difference is the surprising dip in the nacelle surge acceleration at the heart of the wave energy frequency range $(\sim 0.08 \mathrm{~Hz})$. This behavior is attributed to the semi-submersible platform dynamics and is not influenced in any meaningful way by the turbine's operation (e.g. see [30]).

Fig. 12 shows the FF configuration phase shifts for nacelle surge acceleration in addition to the changes from these phase shifts resulting from various controller configurations. Unlike the nacelle surge acceleration and platform pitch PSDs, the FF nacelle acceleration phases and the changes to these phases resulting from the controllers are quite distinct from the platform pitch phasing of Fig. 10. However, similarities do exist with regard to other trends. In particular, as was observed for platform pitch, the controllers yield similar types of phasing changes in the wind excitation range relative to one another and little to no phase change in the wave energy range for nacelle surge acceleration.

Table 7 displays the FF nacelle surge acceleration statistics and changes to these statistics obtained via different turbine controllers. As seen in the table, the mean changes marginally. It should be noted that the mean is non-zero since the surge acceleration sensor is aligned with the turbine, which possesses a small mean inclination due to wind load (i.e., a mean pitch value as shown in Table 6). As a result, a small component of the acceleration due to gravity is recorded in the surge direction by the sensor. This noted, Table 7 shows that controllers each diminish the standard deviation and range of the nacelle surge acceleration; however, each of the reductions is less than $8 \%$ with no particular control scheme distinguishing itself as the best performer in this regard.

\subsection{Mooring Loads}

Upwind fairlead tension PSDs for the FF configuration as well as the deviation from this configuration arising from different turbine control schemes are shown in Fig. 13. As seen in Fig. 13a, the fairlead tension exhibits strong responses at both the damped natural platform surge frequency as well as in the wave energy frequency range. The response at the damped natural platform surge frequency arises from nonlinear catenary action reacting to platform slow-drift surge motion; the response in the wave energy frequency range results from viscous drag on the line reacting to the heave motion of the floating platform (e.g. see [31]). From Fig. 13b, it is observed that each of the three controllers reduces the low frequency fairlead tension response with the CS100 providing the largest reductions. Unlike the other quantities investigated thus far, the controllers also have a small influence on the response in the wave energy frequency range. The CS100 and VS controllers each provide an overall marginal reduction in the wave energy frequency range; the CS25 controller yields a slight increase in this range. Despite this unique behavior relative to the other quantities investigated in this work, wind turbine aerodynamic loads more strongly alter the platform surge response as compared to the platform heave response and therefore the primary controller fairlead tension influence resides at the damped natural platform surge frequency.

The upwind fairlead tension response phasing for the FF case, and deviations from this case for various turbine controllers, is given in Fig. 14. Similar to other quantities investigated, the controller does not significantly influence the phasing in the wave energy frequency range 
despite the alterations in the PSDs at these frequencies found in Fig 13b. The changes in the phasing in the wind excitation regime are quite different between the controllers from 0.02-0.05 $\mathrm{Hz}$ with the CS25 controller causing the largest response phase deviations.

Table 8 displays the upwind fairlead tension statistics for the FF configuration in addition to the changes resulting from the three turbine controllers. For all cases, the mean tension is essentially the same. All of the controllers yield reductions in the standard deviation and range, with the CS100 and VS control schemes yielding the largest reductions.

\subsection{Controller Response}

As just discussed, active turbine controls can yield desirable reductions in floating wind turbine motions and loads. However, these improvements do not come for free; the active turbine controllers studied here can exhibit frequent blade pitch motion, changes in the reactive generator torque, variations in rotor speed about the nominal operating value and changes in aerodynamic rotor thrust. It should be noted that power, which is the product of the reactive generator torque and rotor speed, is not considered here. With near constant rotor speeds for three of the scenarios (FF, CS25 and CS100) and a fourth (VS) with a mean rotor speed similar to the three fixed-speed cases, the power statistics gathered from testing exhibit the same trends as those obtained for the reactive generator torque and provide little additional insight. That aside, Fig. 15 displays the mean, plus/minus one standard deviation and the range of the blade pitch angle for all of the controllers. As seen in the figure, the CS25 controller shows the largest range and the CS100 scheme the greatest standard deviation. The VS controller exhibits the smallest blade pitch angle standard deviation and range of all the active controllers.

The generator torque response for each of the control strategies is given in Fig. 16. Unsurprisingly, the base FF scheme shows the greatest variation in the generator torque. For this case, the magnitude of the standard deviation is larger than the mean generator torque. The responses for the CS25 and CS100 are similar to one another with regard to generator torque; the VS controller exhibits the least variation in generator torque. As per the control scheme discussed earlier, the torque should be more or less constant for the VS scheme. However, as seen in Fig. 16, the actual implementation of the torque controller for the VS configuration did show some variation in the generator torque. Some of this is due to dips in the rotor speed below the target $12.1 \mathrm{rpm}$ where the generator torque is proportional to the square of the rotor speed. These periodic dips below the rated torque also gave rise to a mean torque less than the three fixed rotor speed configurations, and thus, an overall lower turbine power output. Of the three fixed rotor speed control schemes, the fixed blade pitch scheme produces the lowest average torque, and hence turbine power. This may be due to the fact that the blade airfoil angles of attack could have varied widely in the presence of dynamic wind with no blade pitch actuation yielding angles of attack corresponding to low lift (very low angles of attack) or high drag (large angles of attack), both of which would have diminished torque and power output.

To continue the controller response investigation, data regarding rotor speed performance for all the controllers is given in Fig. 17. As seen in the figure, the FF, CS25 and CS100 configurations all exhibit very tight ranges on the rotor speed as a result of their constant rotor speed control scheme. The VS controller, unsurprisingly, shows by far the largest standard deviation and range on rotor speed of any of the turbine controllers. The VS rotor speed range was $55 \%$ of the mean value, a range that is a bit larger than one would expect from a commercial land-based wind turbine. 
Lastly, the aerodynamic rotor thrust response produced by the various control schemes is provided in Fig. 18. The thrust force displayed in the figure is measured from the tower-top load cell and is corrected for nacelle and rotor inertial effects using accelerometer data. That aside, the active controllers tend to reduce the standard deviation and range of the aerodynamic thrust as illustrated in Fig. 18, this being consistent with what one would expect of an active turbine controller. The mean values for the FF and three active are slightly different and follow the trend found for the generator torque with the highest mean value observed for the CS100 configuration and the lowest for the VS controller. And since the aerodynamic thrust force is the primary contributor to the overturning moment applied to the floating wind turbine, the findings for the mean aerodynamic thrust in Fig. 18 are consistent with the statistics given in Table 6 wherein the CS100 controller elicits the largest mean platform pitch angle and the VS arrangement the smallest mean platform pitch angle.

\section{Discussion}

\subsection{Platform Pitch Dynamics}

As revealed in the platform pitch free-decay tests, an operating wind turbine increases platform pitch damping; however, from the available data it is hard to distinguish if the controllers studied here alter this damping in a strong manner. The more prominent change in platform pitch dynamics is revealed to be an elongation of the platform pitch damped natural period that results from a suspected controller-induced reduction in the effective platform pitch stiffness that increases with increasing controller gain. Period elongations of over $10 \%$ were observed. While the performance of the floating wind turbine system in the face of combined wind and wave loading did not seem to be adversely affected by this change in the effective platform stiffness, designers may wish to consider this effect in stability and modal analyses for floating wind turbine systems. For example, the controller-induced reduction in effective platform pitch stiffness could detract from platform pitch motion improvements obtained through management of aerodynamic loads via turbine controls. Conversely, designers could utilize the elongation in platform pitch period to actively assist in avoiding platform excitation from the wave energy frequency range for operational sea states.

\subsection{Global Performance Trends}

When compared to the base FF configuration, the active turbine controllers generally reduced motions and loads, a positive result. In some instances, the reductions were consistently significant as it was for the platform surge position. In others, such as the nacelle surge acceleration, the reductions were uniformly marginal. Regardless of the change, these alterations in global performance were almost exclusively the result of modifying the low-frequency response with the only exception being the upwind fairlead tension PSD which exhibited some small deviations in behavior in the higher-frequency, wave energy range. This overall trend of low-frequency response modification was reinforced through investigation of the response phasing relative to the environmental excitation. The controllers significantly alter the response phasing relative to the low-frequency wind excitation for all of the motion and load parameters considered. The response phasing relative to the higher-frequency wave excitation was hardly altered for any of the quantities investigated, including the mooring load. 
428 For the CS25 constant rotor speed controller, which used a smaller gain than its CS100 counterpart, the slow blade pitch actuation response ultimately led to the largest pitch actuation range of any of the controllers considered. This slow control response also produced, on average, the smallest improvements in global performance of the floating wind turbine for any of the field variables investigated.

The higher gain constant speed controller, the CS100, exhibited the most active blade pitch motion as evidenced by it possessing the largest blade pitch angle standard deviation of any controller investigated. This control scheme yielded the largest reductions in the surge response; however, the CS100 controller exhibited large increases in the platform pitch response at the platform pitch damped natural period. This is not entirely unexpected as blade pitch controllers that operate at high frequencies have been shown through simulation to create platform pitch resonance issues (e.g. see [3]).

\subsection{VS Controller}

The most realistic blade pitch controller studied, the VS controller, overall showed the best improvement in platform motions and loads of all the controllers studied. In particular, the controller distinguished itself in its reduction of platform pitch motions relative to the other controllers. This improved performance also comes with the least variation in the blade pitch angle actuation, a desirable result. However, the rotor speed variation that accompanies this improved global performance is fairly significant indicating that much of the kinetic energy that would have been expressed as platform surge or pitch motion is likely being conveyed to the rotor.

\subsection{Performance Gains and Their Trade Offs}

452

Overall, the experimental data suggests that tuning of active turbine controls can influence global motions and loads for a floating wind turbine, often for the better. That stated, these improvements are often not without consequence as they are achieved at the expense of undesirable increases in blade pitch actuation motion and/or rotor speed variation. In short, floating wind turbine controller design may best be served by striking a balance between power regulation, load mitigation and controller actuator duty.

\subsection{Applicability to Full-Scale Systems}

The data given is this work uses a wind turbine and control schemes tuned to function in the lowReynolds number, Froude-scaled environment of a wind/wave basin. This results from the fact that the turbine aerodynamic sensitivities, for example the change in power with respect to a change in blade pitch angle, are not true to scale. As such, the findings presented in this work may not accurately represent the influence of active turbine controls on the full-scale behavior of a floating wind turbine. That said, the use of properly Froude-scaled wind environments along with a performance-matched wind turbine that preserves aerodynamic thrust performance should emulate the general trends one would observe of controller-induced floating system behavior at full-scale. Definitively resolving the discrepancy between model-scale and full-scale floating wind turbine controller behavior should be pursued in future work. 


\section{Acknowledgements}

470 The financial support from the Department of Energy through DeepCwind Grants DE471 EE0002981 and DE-EE0003728, the National Science Foundation through Grant IIP-0917974

472 and the University of Maine is gratefully acknowledged by the authors. In addition, the expertise 473 and support of MARIN in conducting the model tests is greatly appreciated. 


\section{References}

[1] Musial, W, Butterfield, S, and Ram, B (2006). "Energy from offshore wind," Proc Offshore Tech Conf, Houston, Texas, OTC 18355.

[2] Namik, H and Stol, K (2013). Handbook of Power Systems, Energy Systems, Springer Verlag, 415-445. Eds. Pardalos, PM, Rebennack, S, Pereira, MVF, Iliadis, NA, and Pappu, $\mathrm{V}$.

[3] Jonkman, JM (2008). "Influence of control on the pitch damping of a floating wind turbine," Proc ASME Wind Energ Symp, Reno, Nevada.

[4] Bakka, T and Karimi, HR (2012). "Robust H-infinity dynamic output feedback control synthesis with pole placement constraints for offshore wind turbine systems," Math Prob Eng, 616507.

[5] Christiansen, S, Bak, T, and Knudsen, T (2013). "Damping wind and wave loads on a floating wind turbine," Energies, 6, 4097-4116.

[6] Lackner, MA (2013). "An investigation of variable power collective pitch control for load mitigation of floating offshore wind turbines," Wind Energ, 16, 519-528.

[7] Larsen, TJ and Hanson, TD (2007). "A method to avoid negative damped low frequent tower vibrations for a floating, pitch controlled wind turbine," Sci of Making Torque from Wind, J Phy: Conf Series, 75, 012073.

[8] Lineberg, E, Svendsen, HG, and Uhlen, K (2012). "Smooth transition between controllers for floating wind turbines," Energy Procedia, 24, 83-98.

[9] Namik, H and Stol, K (2011). "Performance analysis of individual blade pitch control of offshore wind turbines on two floating platforms," Mechatronics, 21, 691-703.

[10] Oh, Y, Kim, K, Kim, H, and Paek, I (2015). "Control algorithm of a floating wind turbine for reduction of tower loads and power fluctuation," Int J Precision Eng and Manuf, 16(9), 2041-2048.

[11] Roberto, R (2013). "Actuator saturation control of floating wind turines," Proc 31st ASME Int Conf Ocean, Off and Arctic Eng, Rio de Janeiro, Brazil, 7, 359-367.

[12] Savenije, F and Peeringa, J (2014). "Control development for floating wind," Sci of Making Torque from Wind, J Phy: Conf Series, 524, 012090.

[13] Wang, L, Zuo, S, Song, YD, and Zhou, Z (2014). "Variable torque control of offshore wind turbine on spar floating platform using advanced RBF neural network," Abstract and Appl Anal, 903493.

[14] Azcona, J, Bouchotrouch F, Gonzalez, M, Garciandia, J, Mundate, X, Kelberlau, F, and Nygaard, TA (2014). "Aerodynamic thrust modelling in wave tank tests of offshore wind turbines using a ducted fan," Sci of Making Torque from Wind, J Phy: Conf Series, 524, 012089.

[15] Huijs, F, de Ridder, E-J, and Savenije, F (2014). "Comparison of model tests and coupled simulations for a semi-submersible floating wind turbine," Proc 33rd ASME Int Conf Ocean, Off and Arctic Eng, San Francisco, California, 10 pp.

[16] Skaare, B, Nielsen, FG, Hanson, TD, Yttervik, R, Havmoller, O, and Rekdal, A (2015). "Analysis of measurements and simulation from the Hywind Demo floating wind turbine," Wind Energ, 18, 1105-1122.

[17] Viselli, AM, Goupee, AJ, and Dagher, HJ (2015). "Model test of a 1:8 scale floating wind turbine offshore in the Gulf of Maine," J Off Mech Arct Eng, 137(4), 041901-1. 
[18] Chujo, T, Minami, Y, Nimra, T, and Ishida, S (2013). "Experimental study for spar type floating offshore wind turbine with blade-pitch control," Proc 32nd ASME Int Conf Ocean, Off and Arctic Eng, Nantes, France, 7 pp.

[19] Buchner, B, Wichers, JEW, and de Wilde, JJ (1999). "Features of the state-of-the-art Deepwater Offshore Basin," Proc Offshore Tech Conf, Houston, Texas, OTC 10814.

[20] American Petroleum Institute (2000). "Recommended practice for planning and designing and constructing fixed offshore platforms-Working stress design," Recommended Practice API RP 2A-WSD.

[21] International Electrotechnical Commission (2009). "Wind Turbines-Part 3: Design requirements for offshore wind turbines," Design Standatd IEC 61400-3.

[22] Viselli, AM, Forristall, GZ, Pearce, B, and Dagher, HJ (2015). "Estimation of extreme wave and wind design parameters for offshore wind turbines in the Gulf of Maine using a POT method," Ocean Eng, 104, 649-658.

[23] de Ridder, E-J, Otto, W, Zondervan, G-J, Huijs, F, and Vaz, G (2014). Development of a scaled-down floating wind turbine for offshore basin testing," Proc 33rd ASME Int Conf Ocean, Off and Arctic Eng, San Francisco, California, 11 pp.

[24] Kimball, R, Goupee, AJ, Gowler, MJ, de Ridder, E-J, and Helder, J (2015). "Wind/wave basin verification of a performance-matched scale-model wind turbine on a floating offshore wind turbine platform," Proc 33rd ASME Int Conf Ocean, Off and Arctic Eng, San Francisco, California, $10 \mathrm{pp}$.

[25] Goupee, AJ, Fowler, MJ, Kimball, RW, Helder, J, and de Ridder, E-J (2014). “Additional wind/wave basin testing of the DeepCwind semi-submersible with a performance-matched wind turbine," Proc 33rd ASME Int Conf Ocean, Off and Arctic Eng, San Francisco, California, $10 \mathrm{pp}$.

[26] Jonkman, JM, Butterfield, S, Musial, W, and Scott, G (2009). "Devinition of a 5-MW reference wind turbine for offshore system development," NREL/TP-500-38060.

[27] Manwell, JF, McGowan, JG, and Rogers, AL (2009). Wind Energy Explained: Theory, Design and Applications, $2^{\text {nd }}$ Ed, Wiley, $689 \mathrm{pp}$.

[28] Jonkman, JM (2007). "Dynamics modeling and loads analysis of an offshore floating wind turbine," NREL/TP-500-41958.

[29] Coulling, AJ, Goupee, AJ, Robertson, AN, Jonkman, JM, and Dagher, HJ (2013). "Validation of a FAST semi-submersible floating wind turbine numerical model with DeepCwind test data," J Renew Sust Energ, 5, 023116.

[30] Goupee, AJ, Koo, BJ, Kimball, RW, Lambrakos, KF, and Dagher, HJ (2014). "Experimental comparisons of three floating wind turbine concepts," J Off Mech Arct Eng, 136(2), 020906-1.

[31] Hall, M and Goupee, A (2015). "Validation of a lumped-mass mooring line model with DeepCwind semisubmersible model test data," Ocean Eng, 104,590-603. 


\begin{tabular}{|l|l|l|l|}
\hline Mean $(\mathrm{m} / \mathrm{s})$ & $\sigma(\mathrm{m} / \mathrm{s})$ & Max. $(\mathrm{m} / \mathrm{s})$ & Min. $(\mathrm{m} / \mathrm{s})$ \\
\hline 21.02 & 2.15 & 30.00 & 12.93 \\
\hline
\end{tabular}

\begin{tabular}{|l|l|l|l|l|}
\hline$H_{s}(\mathrm{~m})$ & $T_{p}(\mathrm{~s})$ & Max. $(\mathrm{m})$ & Min. $(\mathrm{m})$ & $H_{\max }(\mathrm{m})$ \\
\hline 7.05 & 12.09 & 7.47 & -6.69 & 13.17 \\
\hline
\end{tabular}

Table 2. Statistics for the irregular wave.

561

\begin{tabular}{|l|l|}
\hline Rotor Diameter (m) & 126.0 \\
\hline Hub Height (m) & 90.0 \\
\hline Draft (m) & 20.0 \\
\hline Mooring Spread Diameter (m) & 1675 \\
\hline Mass w/ Turbine (MT) & 13,958 \\
\hline Displacement (MT) & 14,265 \\
\hline Center of Gravity Above Keel (m) & 11.93 \\
\hline Roll Radius of Gyration (m) & 32.63 \\
\hline Pitch Radius of Gyration (m) & 33.38 \\
\hline Tower Fore-aft Bending Frequency (Hz) & 0.32 \\
\hline
\end{tabular}

563

Table 3. Gross properties of the DeepCwind-OC5 floating wind turbine.

\begin{tabular}{|l|l|l|l|l|}
\hline Blade Pitch $\theta$ & Rotor Speed (rpm) & $\begin{array}{l}\text { Controller } \\
\text { Setting }\end{array}$ & $\begin{array}{l}\text { Pitch } \\
\text { Period (s) }\end{array}$ & $\begin{array}{l}\Delta C_{\text {Pitch }} \\
(\%)\end{array}$ \\
\hline $90.0^{\circ}$ & 0.0 & N/A & 32.5 & N/A \\
\hline $17.2^{\circ}$ & 12.1 & FF & 32.2 & 1.9 \\
\hline Active & 12.1 & CS25 & 33.2 & -4.2 \\
\hline Active & 12.1 & CS100 & 35.9 & -18.0 \\
\hline Active & Variable & VS & 33.6 & -6.4 \\
\hline
\end{tabular}

Table 4. Platform pitch damped natural periods as measured from free-decay tests and estimated change in platform pitch stiffness.

\begin{tabular}{|l|l|l|l|l|}
\hline & FF (m) & $\Delta$ CS25 (\%) & $\Delta$ CS100 (\%) & $\Delta$ VS (\%) \\
\hline Mean & -7.40 & $2.0 \%$ & $2.3 \%$ & $-0.8 \%$ \\
\hline$\sigma$ & 2.29 & $-24.5 \%$ & $-33.6 \%$ & $-29.7 \%$ \\
\hline Range & 16.39 & $-20.8 \%$ & $-31.8 \%$ & $-22.8 \%$ \\
\hline
\end{tabular}

Table 5. Platform surge statistics for the FF configuration and the deviations for each of the controller schemes. 


\begin{tabular}{|l|l|l|l|l|}
\hline & $\mathrm{FF}\left(^{\circ}\right)$ & $\Delta \mathrm{CS} 25(\%)$ & $\Delta \mathrm{CS} 100(\%)$ & $\Delta \mathrm{VS}(\%)$ \\
\hline Mean & -2.31 & $0.0 \%$ & $5.6 \%$ & $-5.2 \%$ \\
\hline$\sigma$ & 1.52 & $-11.8 \%$ & $-13.8 \%$ & $-28.3 \%$ \\
\hline Range & 11.13 & $-8.4 \%$ & $-6.6 \%$ & $-27.1 \%$ \\
\hline
\end{tabular}

569

570

571

\begin{tabular}{|l|l|l|l|l|}
\hline & $\mathrm{FF}\left(\mathrm{m} / \mathrm{s}^{2}\right)$ & $\Delta \mathrm{CS} 25(\%)$ & $\Delta \mathrm{CS} 100(\%)$ & $\Delta \mathrm{VS}(\%)$ \\
\hline Mean & 0.42 & $7.1 \%$ & $7.1 \%$ & $2.4 \%$ \\
\hline$\sigma$ & 0.52 & $-3.8 \%$ & $-3.8 \%$ & $-7.7 \%$ \\
\hline Range & 4.65 & $-2.6 \%$ & $-5.6 \%$ & $-3.4 \%$ \\
\hline
\end{tabular}

572 Table 7. Nacelle surge acceleration statistics for the FF configuration and the deviations for each 573 of the controller schemes.

574

\begin{tabular}{|l|l|l|l|l|}
\hline & FF (kN) & $\Delta$ CS25 $(\%)$ & $\Delta$ CS100 (\%) & $\Delta$ VS (\%) \\
\hline Mean & 1527.31 & $0.6 \%$ & $0.5 \%$ & $-0.8 \%$ \\
\hline$\sigma$ & 294.57 & $-8.4 \%$ & $-13.0 \%$ & $-12.4 \%$ \\
\hline Range & 3557.49 & $-8.7 \%$ & $-10.5 \%$ & $-11.6 \%$ \\
\hline
\end{tabular}

575 Table 8. Upwind fairlead tension statistics for the FF configuration and the deviations for each 576

of the controller schemes. 


\section{Figure Captions}

578 Fig. 1. DOF and heading of winds and waves for model test.

579 Fig. 2. Target and measured PSDs for the dynamic wind and the irregular sea state.

580 Fig. 3. Images of DeepCwind-OC5 floating wind turbine in MARIN's offshore basin.

581 Fig. 4. Comparison of normalized full-scale target and model wind turbine performance.

582 Fig. 5. Corrected platform pitch free-decay times series for different wind turbine control 583 scenarios.

584 Fig. 6. Platform pitch free-decay damping response for different wind turbine control scenarios.

585 Fig. 7. a) FF configuration platform surge response and b) the deviation from this response for 586 each of the controller schemes.

587 Fig. 8. a) FF configuration platform surge phase shift and b) the deviation from this phase shift 588 for each of the controller schemes.

589 Fig. 9. a) FF configuration platform pitch response and b) the deviation from this response for 590 each of the controller schemes.

591 Fig. 10. a) FF configuration platform pitch phase shift and b) the deviation from this phase shift 592 for each of the controller schemes.

593 Fig. 11. a) FF configuration nacelle surge acceleration response and b) the deviation from this 594 response for each of the controller schemes.

595 Fig. 12. a) FF configuration nacelle surge acceleration phase shift and b) the deviation from this 596 phase shift for each of the controller schemes.

597 Fig. 13. a) FF configuration upwind fairlead tension response and b) the deviation from this 598 response for each of the controller schemes.

599 Fig. 14. a) FF configuration upwind fairlead tension phase shift and b) the deviation from this 600 phase shift for each of the controller schemes.

601 Fig. 15. Turbine controller blade pitch angle response.

602 Fig. 16. Turbine controller generator torque response.

603 Fig. 17. Turbine controller rotor speed response.

604 Fig. 18. Turbine controller aerodynamic rotor thrust response. 
Figure 1

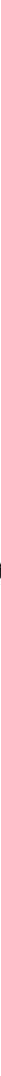

$180^{\circ}$

$0^{\circ}$ 
Figure 2

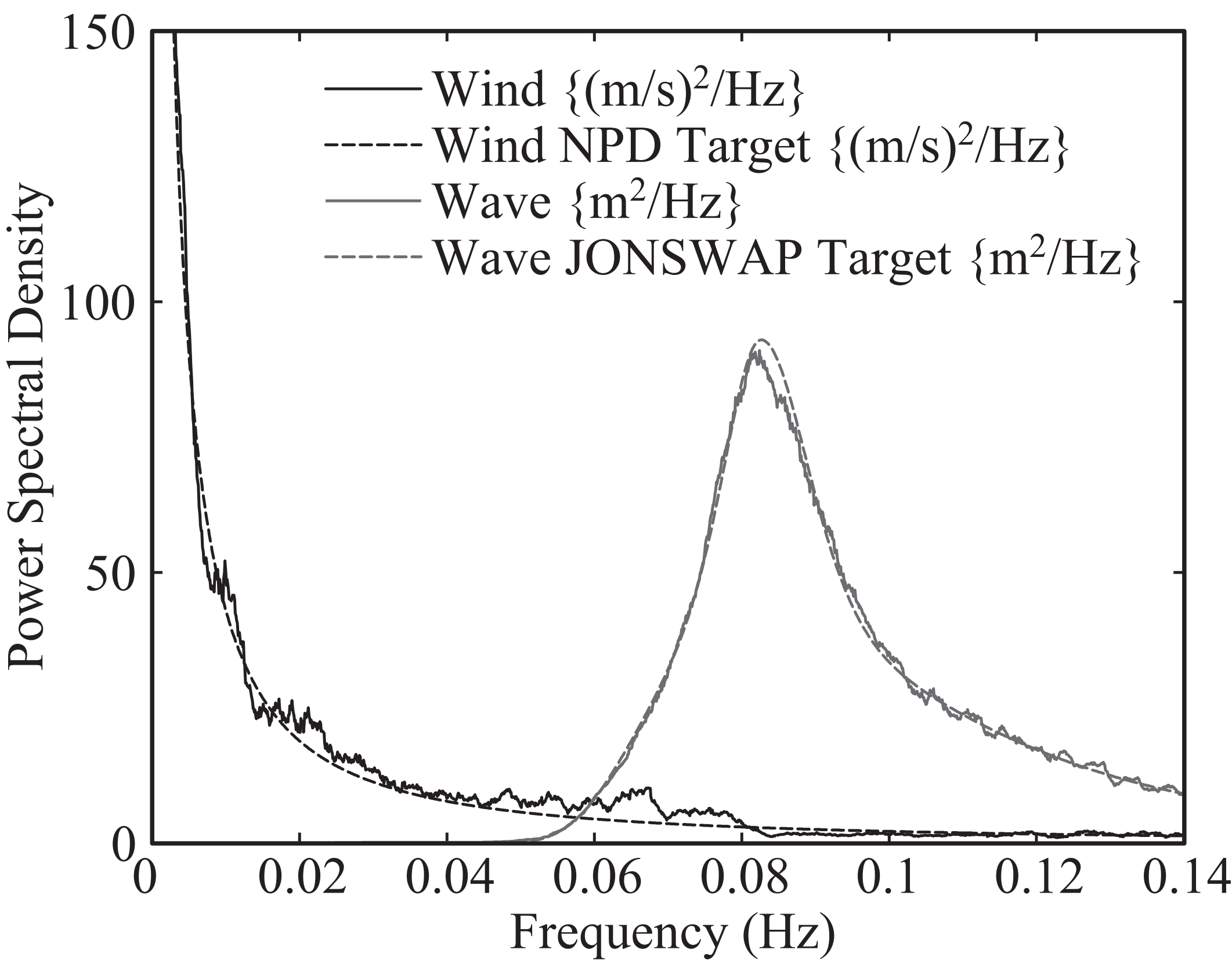




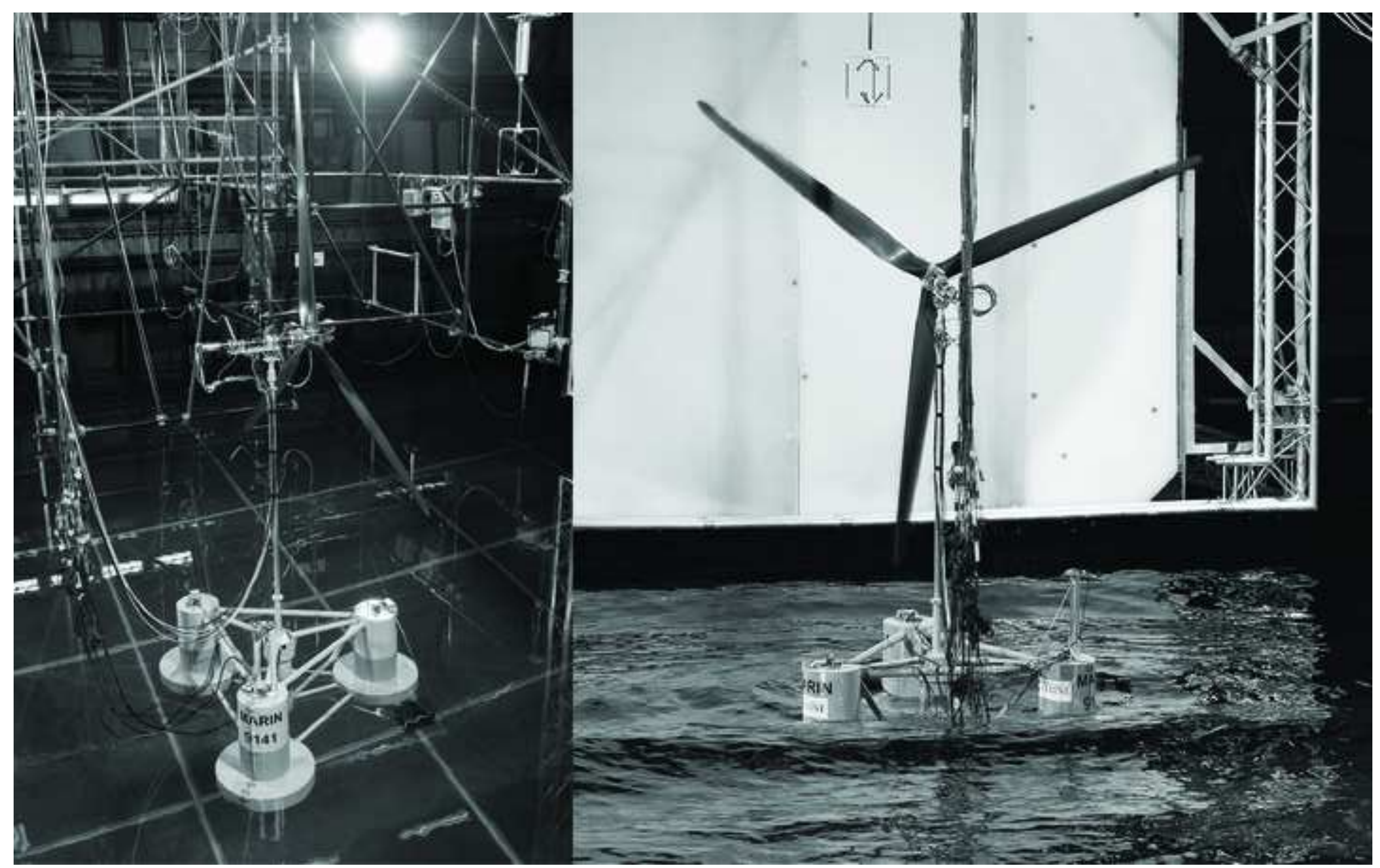


Figure 5

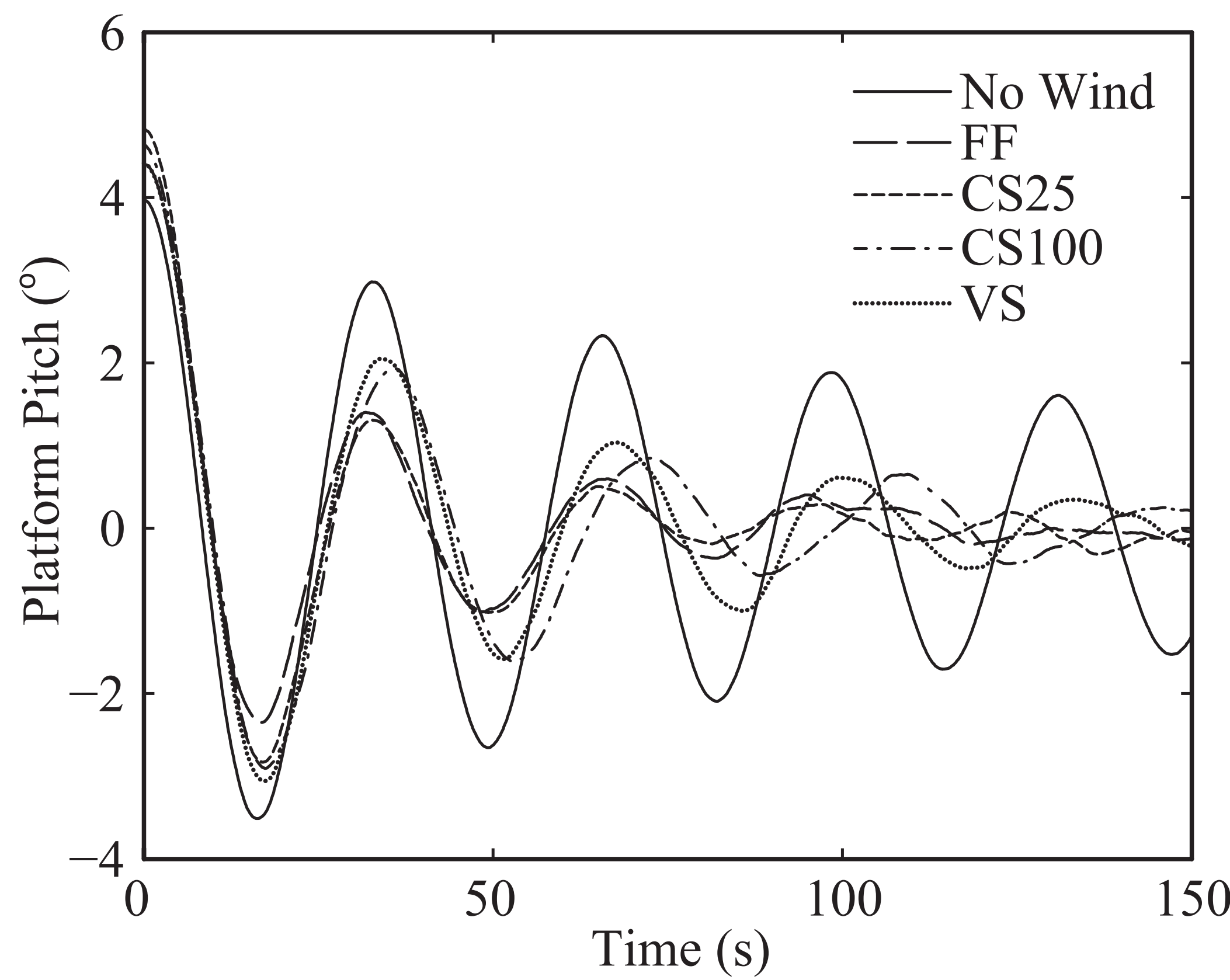

\section{Time (s)}


Figure 6

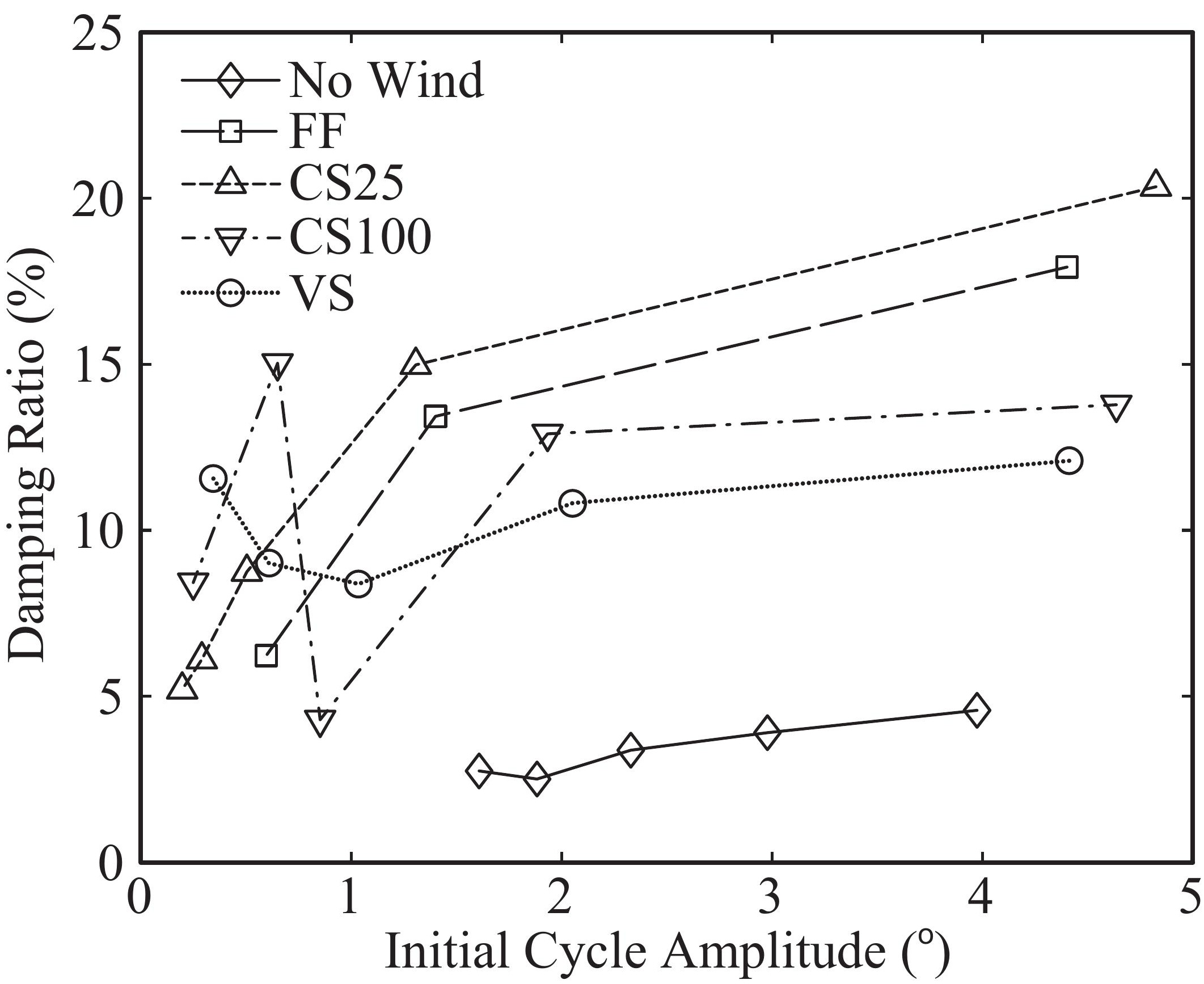


Figure 7
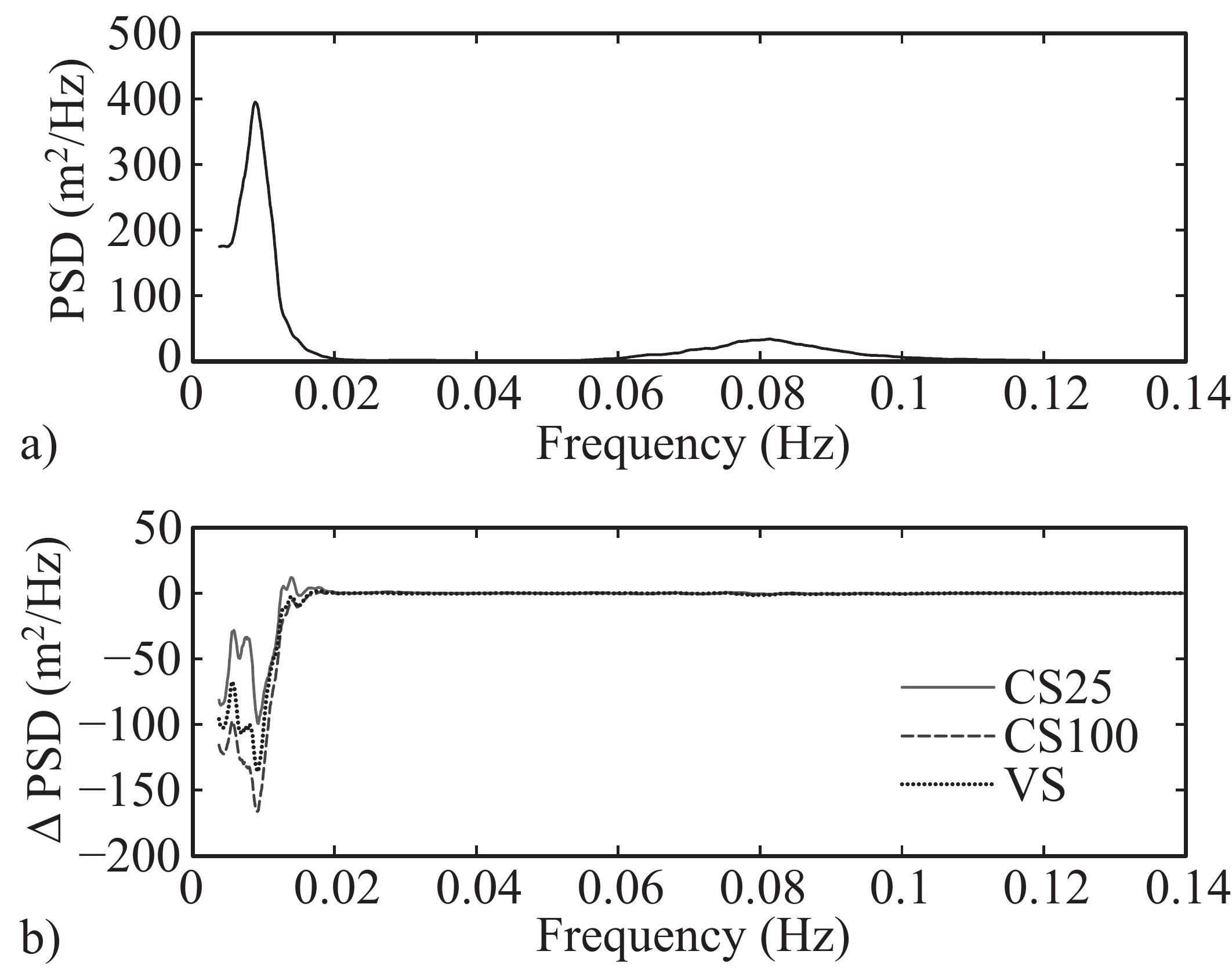

b) 
Figure 8
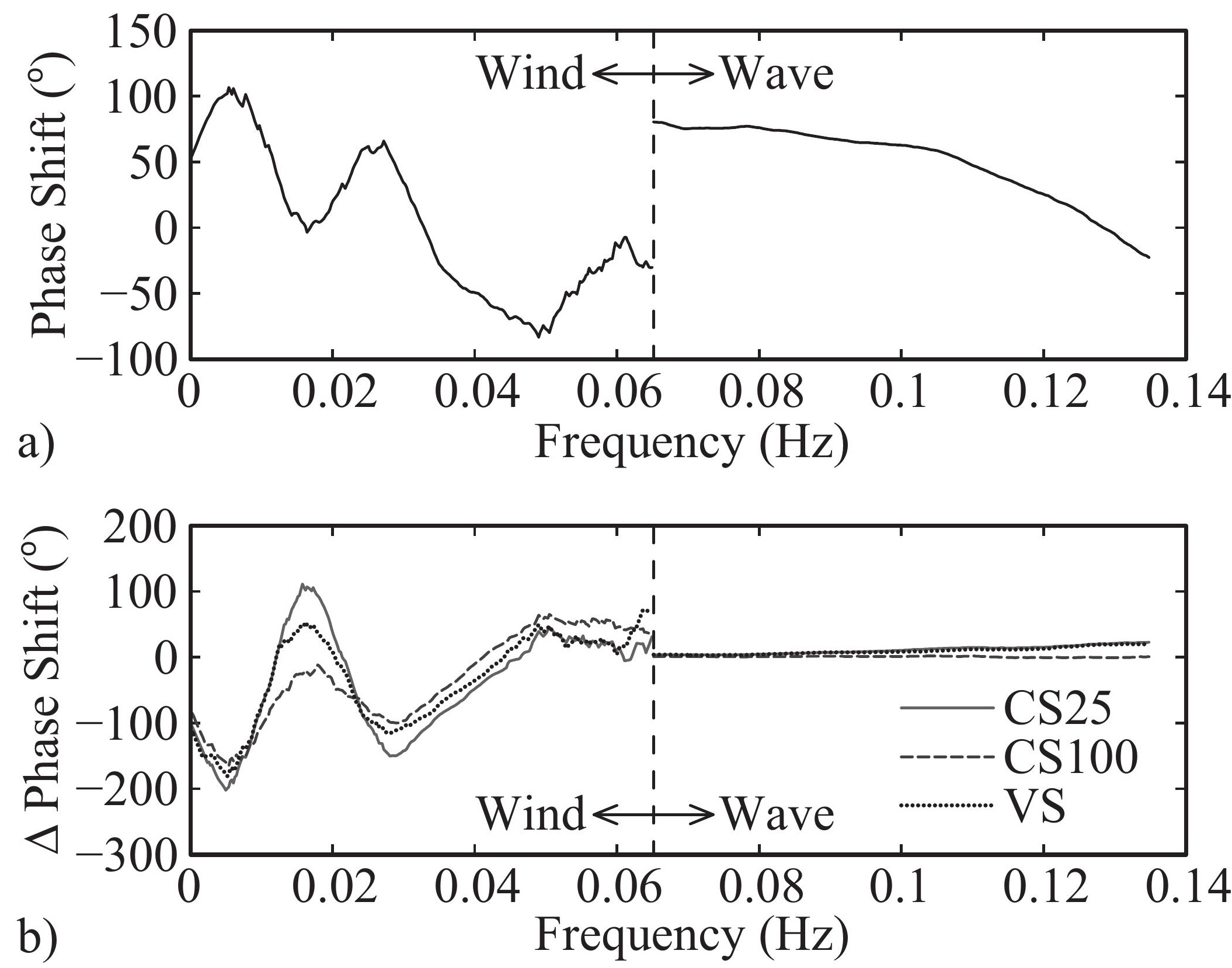

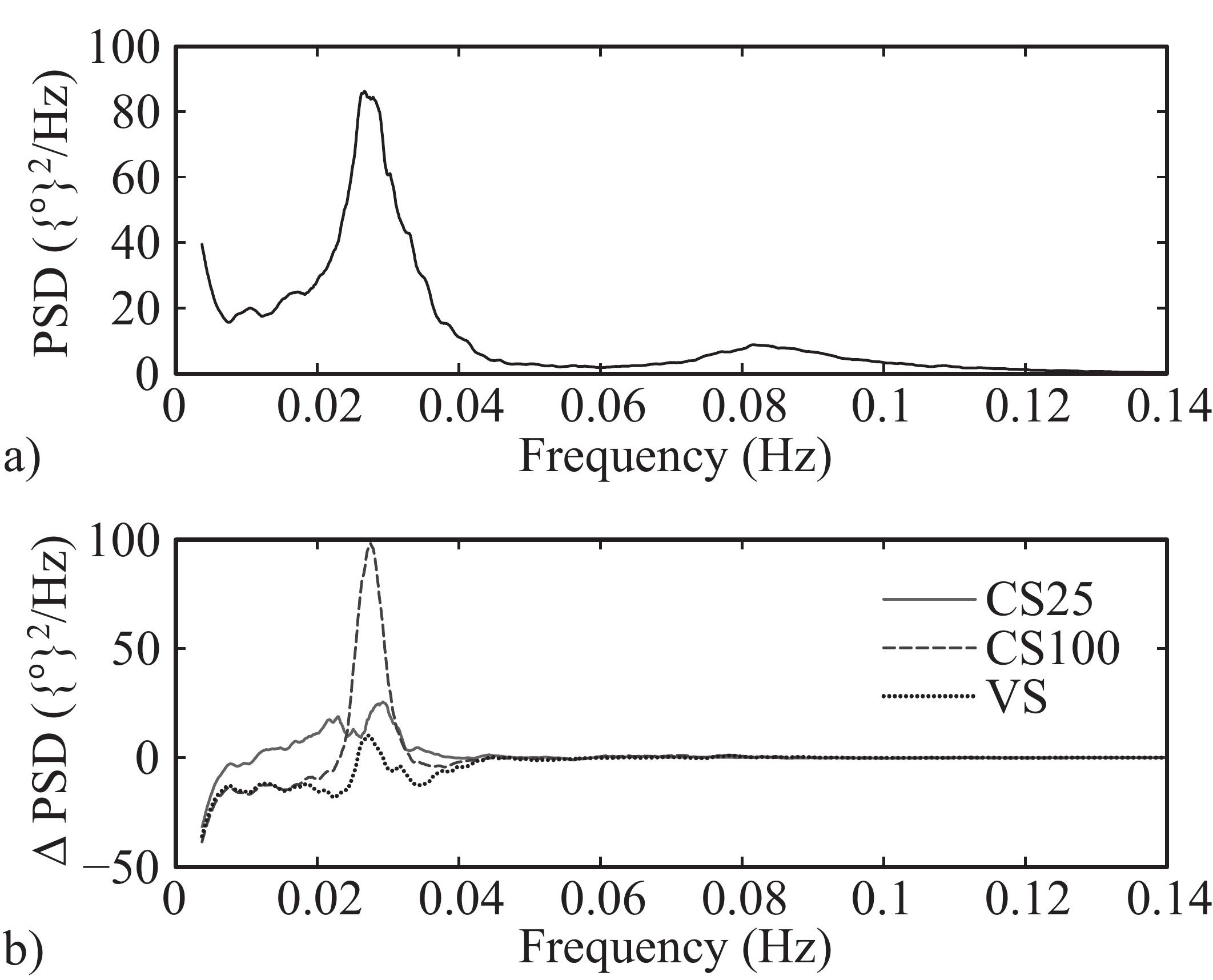

Figure 9 

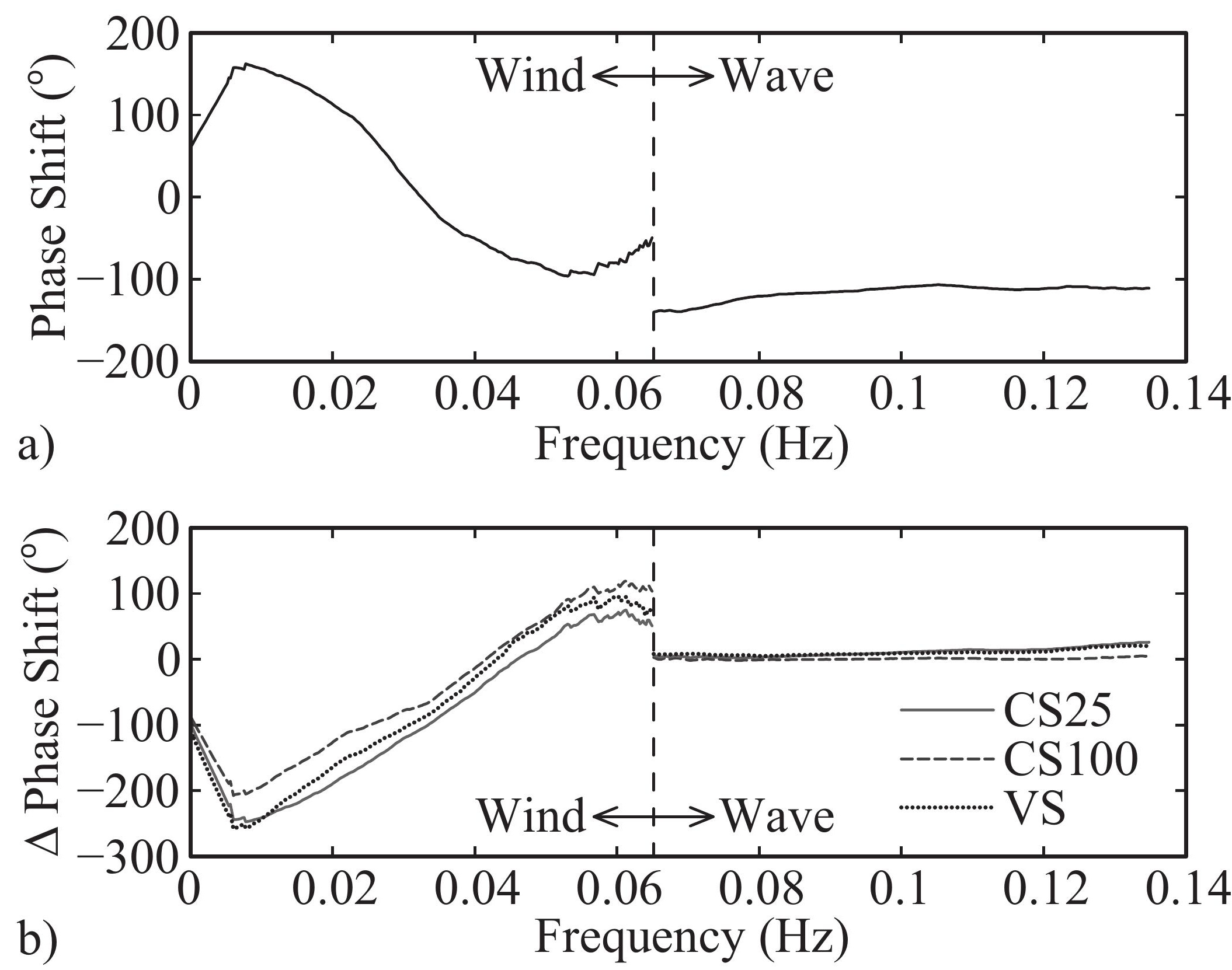

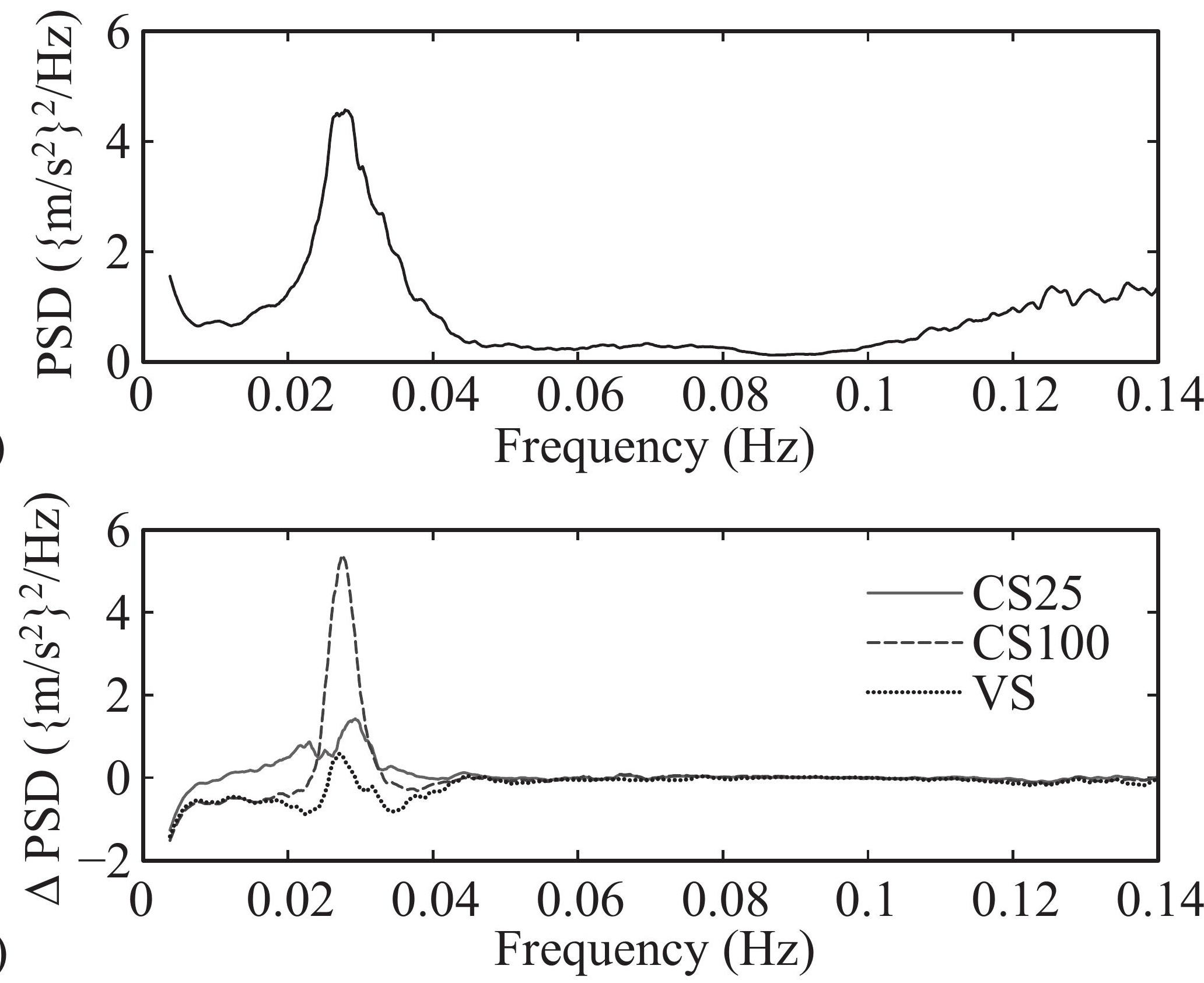

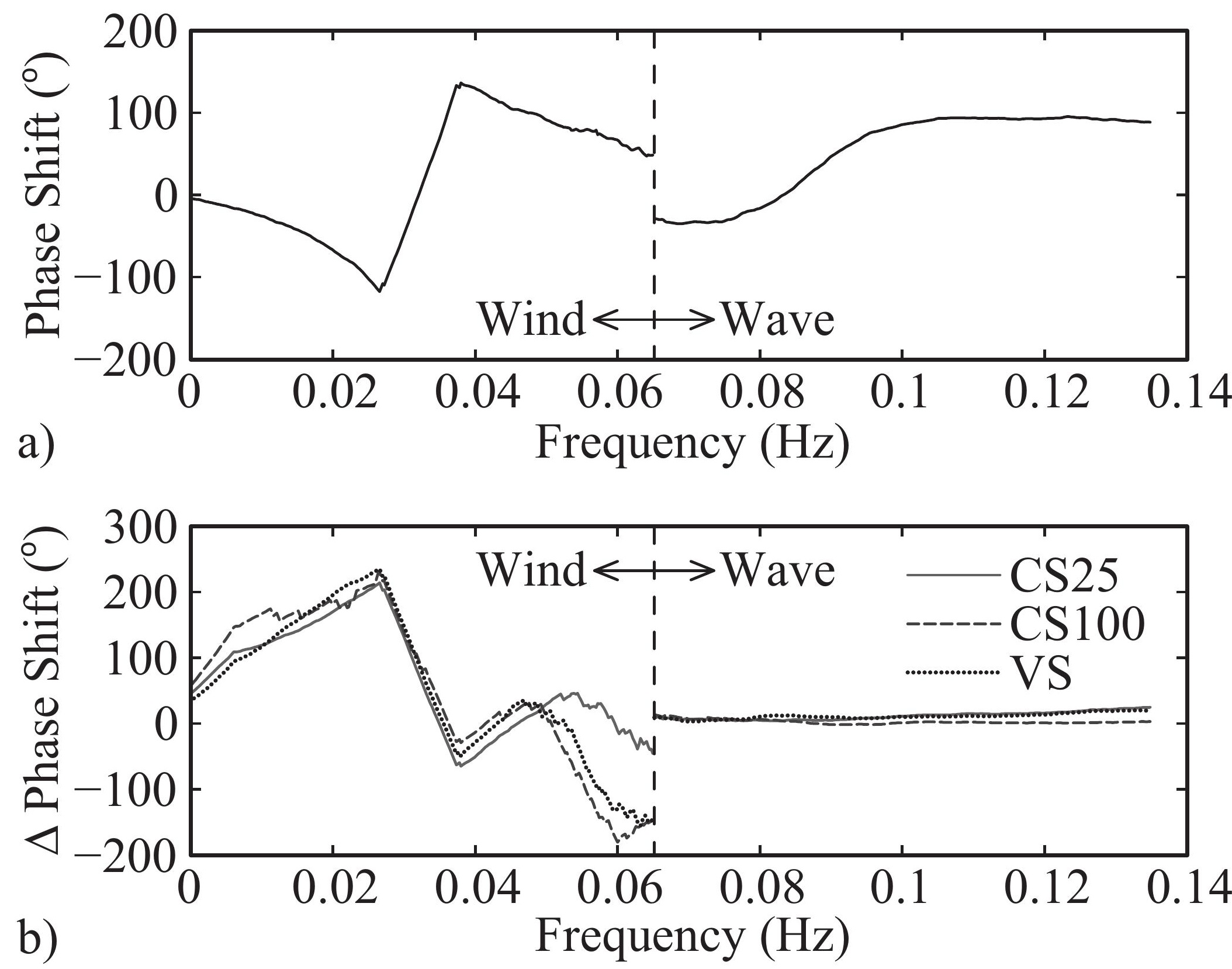

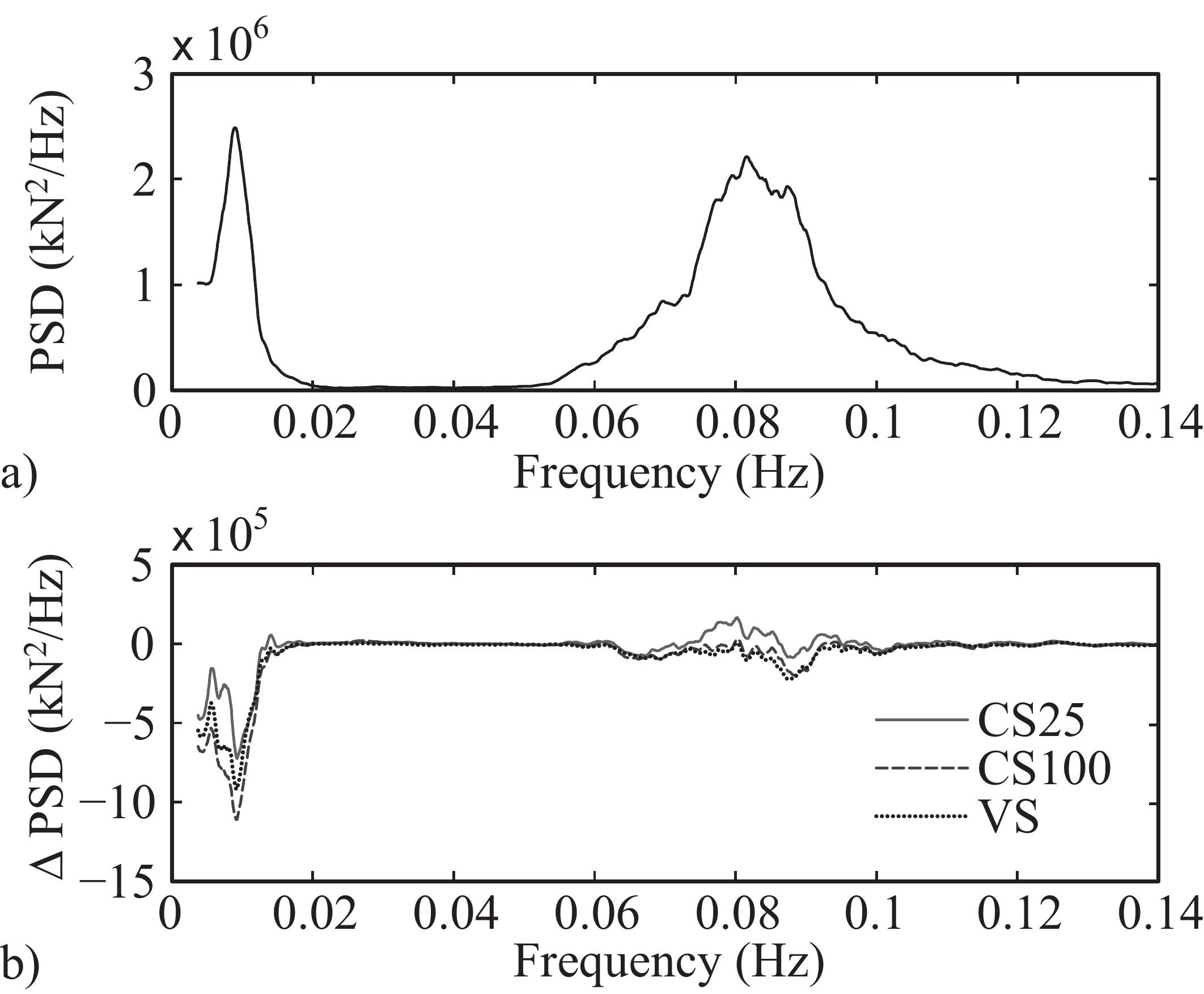

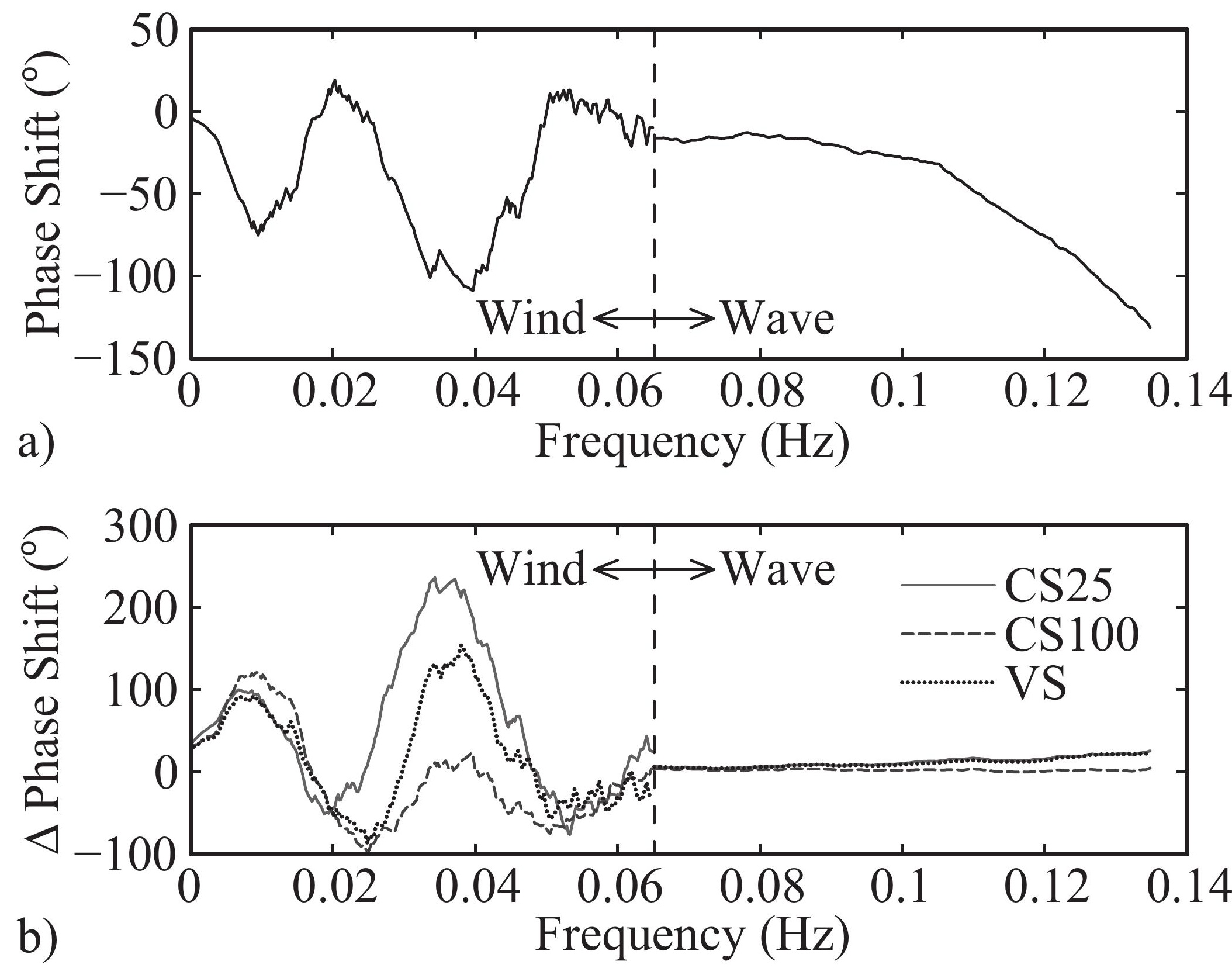


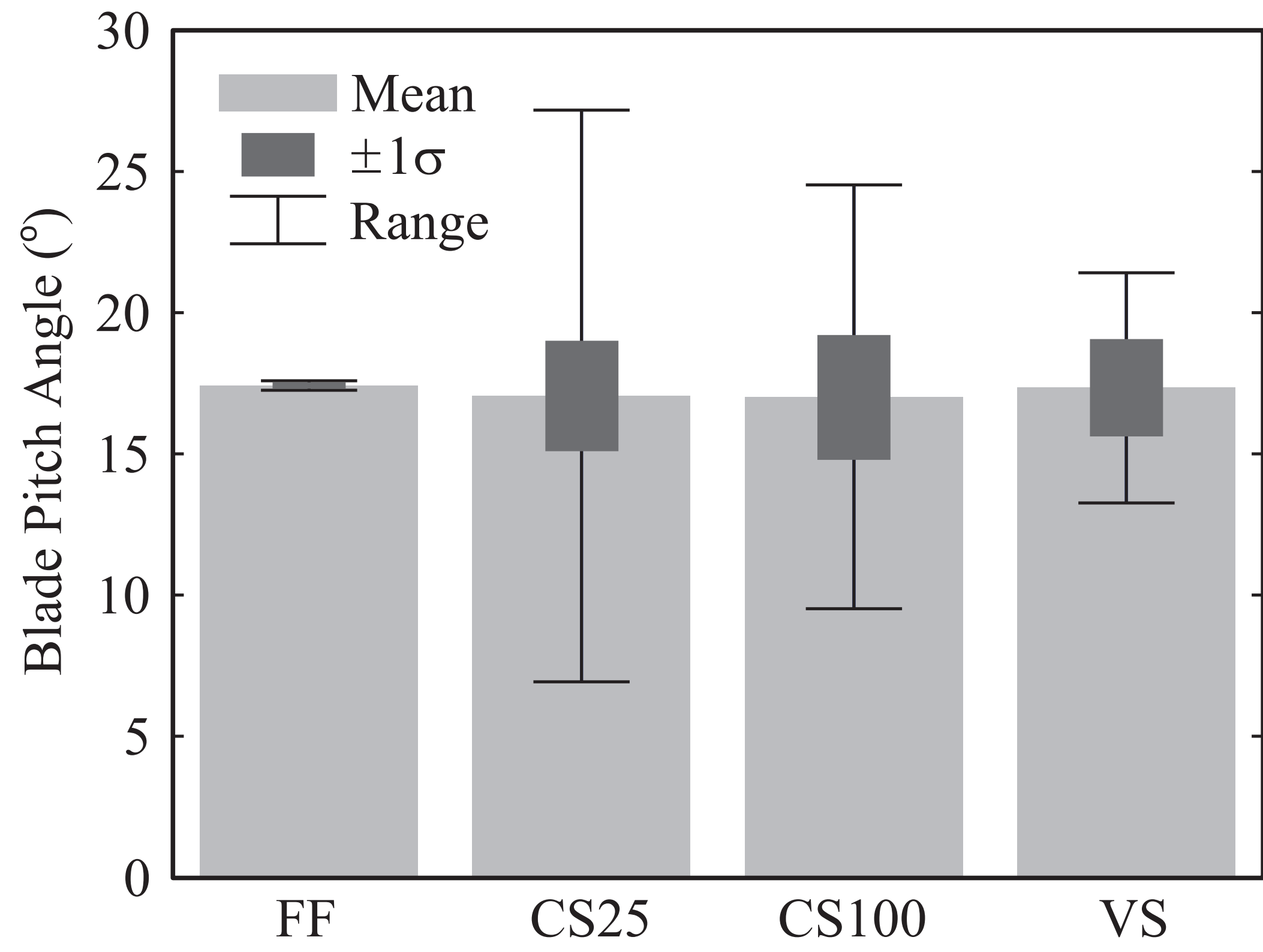


Figure 16

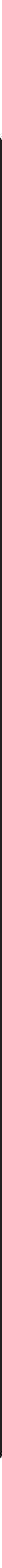

\section{gine 16}

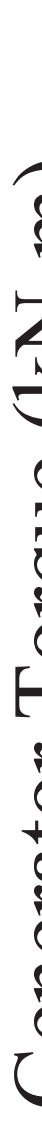

年

. . . . . .

( 


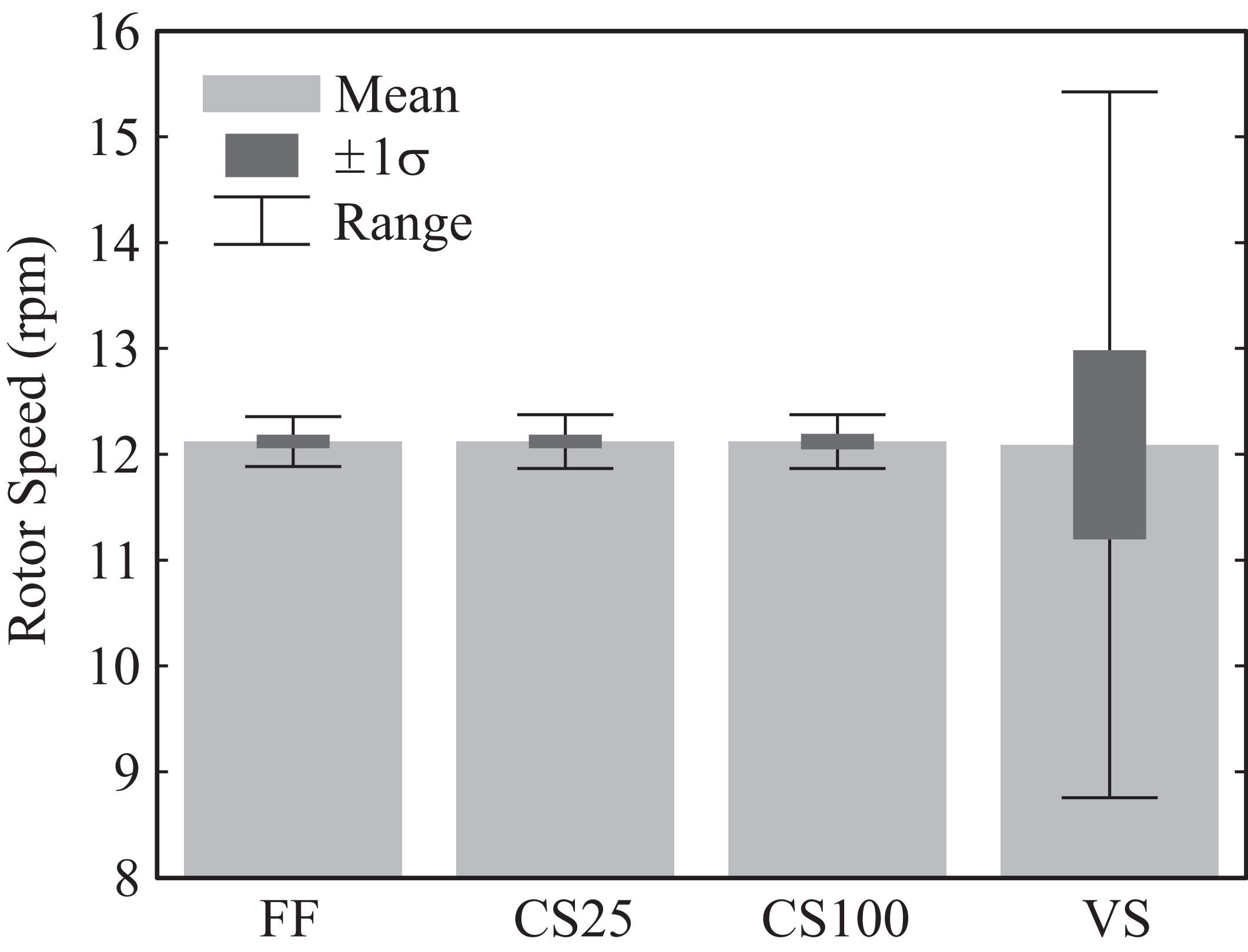

\section{$\begin{array}{llll}\text { FF } & \text { CS25 } & \text { CS100 } & \text { VS }\end{array}$}




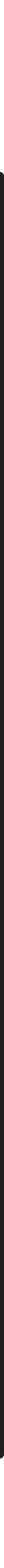

Figure 18 8

$$
\text { . }
$$

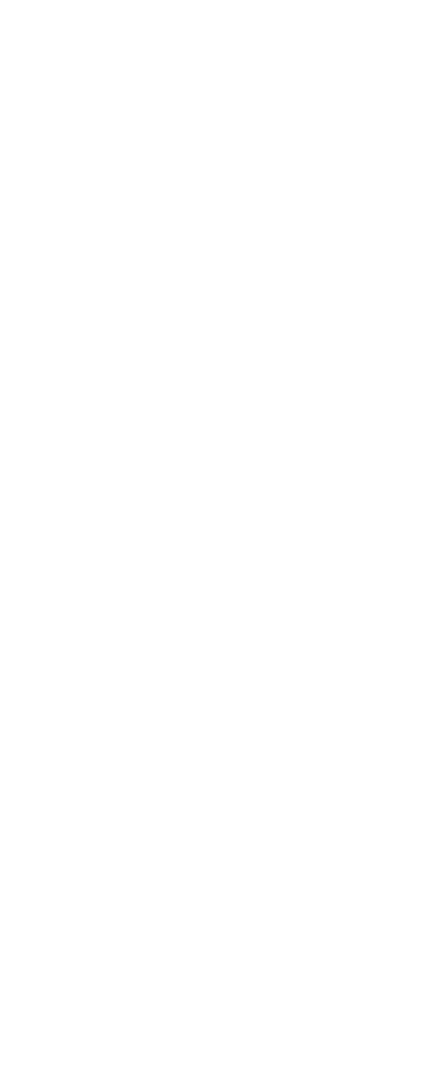

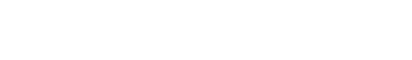
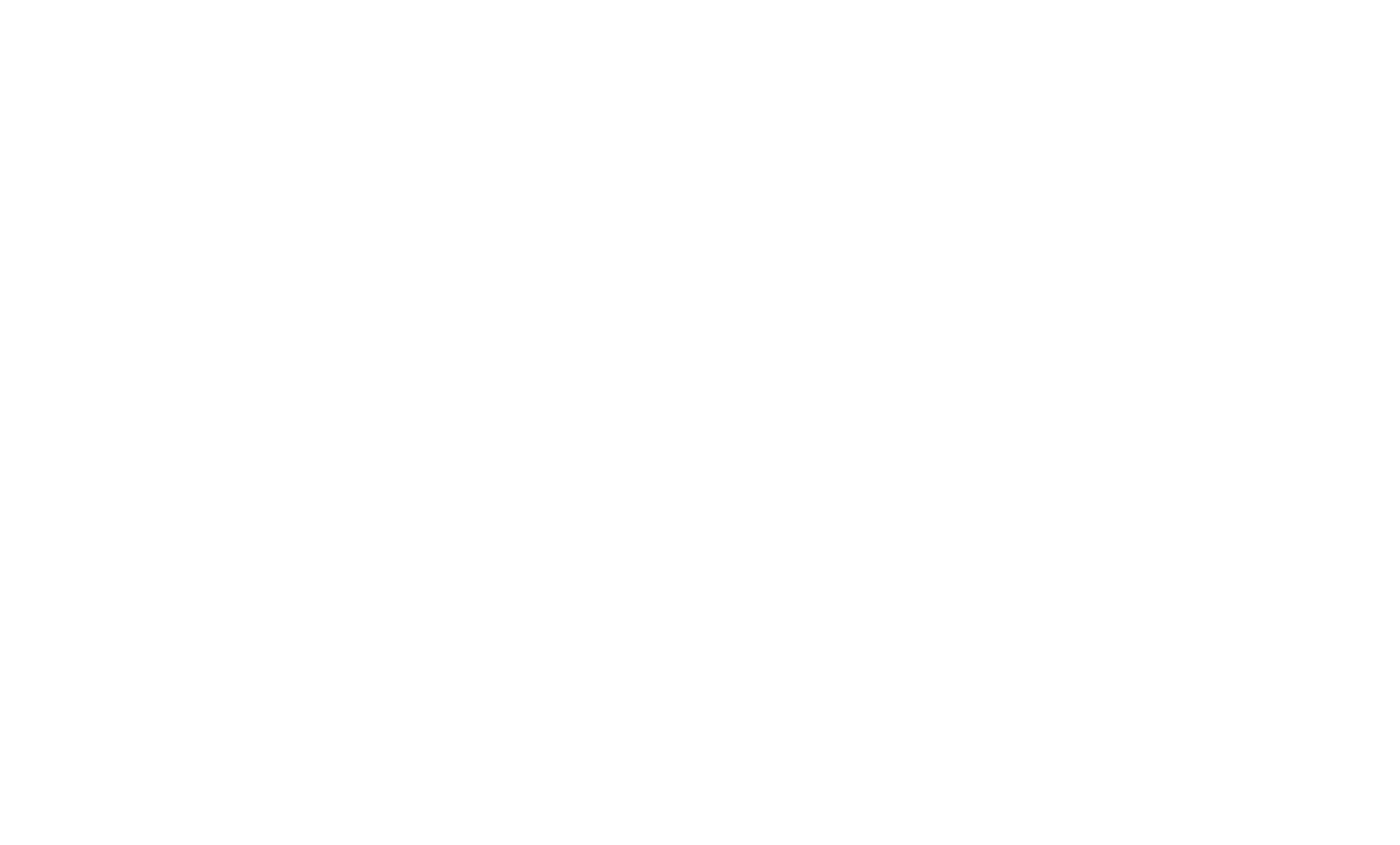